\title{
Cauda Equina Syndrome with Neurogenic Bladder
}

National Cancer Institute

\section{Source}

National Cancer Institute. Cauda Equina Syndrome with Neurogenic Bladder. NCI

Thesaurus. Code C34453.

A rare neurologic disorder caused by impingement of the nerve roots of the cauda equina secondary to disc herniation, spinal stenosis, vertebral fracture, neoplasm or infection. Clinical signs may include bladder or bowel dysfunction, paresthesia and weakness of the lower extremities. The development of neurogenic bladder implies that surgical decompression was either ineffective, delayed or not attempted. 